\title{
SEASONALITY OF METEOROLOGICAL DROUGHT PARAMETERS IN GERMANY AND THEIR TRENDS DUE TO CLIMATE CHANGE
}

\author{
F. SKIERLO ${ }^{1,2}$, J. J. GÓMEZ-HERNÁNDEZ ${ }^{2}$, K. MIEGEL ${ }^{1}$
}

\begin{abstract}
Seasonality of meteorological drought parameters in Germany and their trends due to climate change. Climate change as a global problem affects the world on different scales, but its impact differs strongly between regions. Beside temperature, precipitation is another key element of the climatic system with at least the same importance. Regarding the precipitation regime, not only changes in the mean values have been detected, but also in the occurrence of extreme events and shifts in the seasonal distribution of precipitation throughout the year.

With this background, our study investigates trends of meteorological drought in Germany as an example of what happens in a temperate climate zone. As indicators of dry spells we used the highest annual number of consecutive dry days, and the lowest precipitation within 40 days during one year as a new index. In addition, we analysed the annual and monthly total number of precipitation-free days as well as the total precipitation and its daily average on a monthly basis as further meteorological parameters. The results show an overall increase of the annual precipitation along with a decrease of the number of dry days per year. The highest annual number of consecutive dry days has also been decreasing, which means that dry spells are interrupted more often by significant precipitation and therefore are shorter. In accordance with the annual precipitation, the lowest precipitation during 40 consecutive days has also increased. As expected, the calculated linear trends of the parameters vary within the country and show a seasonal shift with stronger changes in certain month regarding the monthly precipitation, with a clear increase during the winter months. The results obtained using only precipitation-based meteorological parameters and our new index are in accordance with other results from the literature.
\end{abstract}

Keywords: drought, seasonality, trends, climate change, precipitation.

\section{INTRODUCTION}

Climate change as a global problem affects the world on different scales, but it has been shown that its impact regarding the different climatic elements varies strongly between regions. One of the key parameters concerning climatic changes is precipitation. With respect to the precipitation regime, not only changes in the mean values have been detected, but also in the occurrence of extreme events

\footnotetext{
${ }^{1}$ University of Rostock, Faculty of Agricultural and Environmental Sciences, institute HY, Satower Straße 48, 18059 Rostock, Germany; E-mail: freya.skierlo@uni-rostock.de; konrad.miegel@unirostock.de

2 Universitat Politècnica de València, ETSICCP, dept. DIHMA, institute IIAMA, Camino de Vera, s/n, 46022 Valencia, Spain; E-mail: jgomez@upv.es
} 
and shifts in the seasonal distribution of precipitation throughout the year. The focus of this study lies on meteorological drought as the absence of precipitation, and how the occurrence and distribution of precipitation-free days has undergone changes in Germany due to climate change during the last decades.

\section{MATERIAL AND METHODS}

\section{Study Area and Data Basis}

The study area is the whole of Germany as an example of how climate change influences the precipitation regime in the temperate climate zone. The country extends between $47-55^{\circ} \mathrm{N}$ and has a surface of approx. $357,000 \mathrm{~km}^{2}$. Typical for the German climate are winds mainly from the west, which bring humid air from the Atlantic, resulting in precipitation during the whole year. The annual precipitations are $<500-700 \mathrm{~mm}$ in the north, $700->1,500 \mathrm{~mm}$ in the centre and $>2,000 \mathrm{~mm}$ in the south. The climate gradually changes from the north-west to the south-east from oceanic to continental climate. The winters generally are mild and the summers moderately warm (Statistisches Bundesamt 2015).

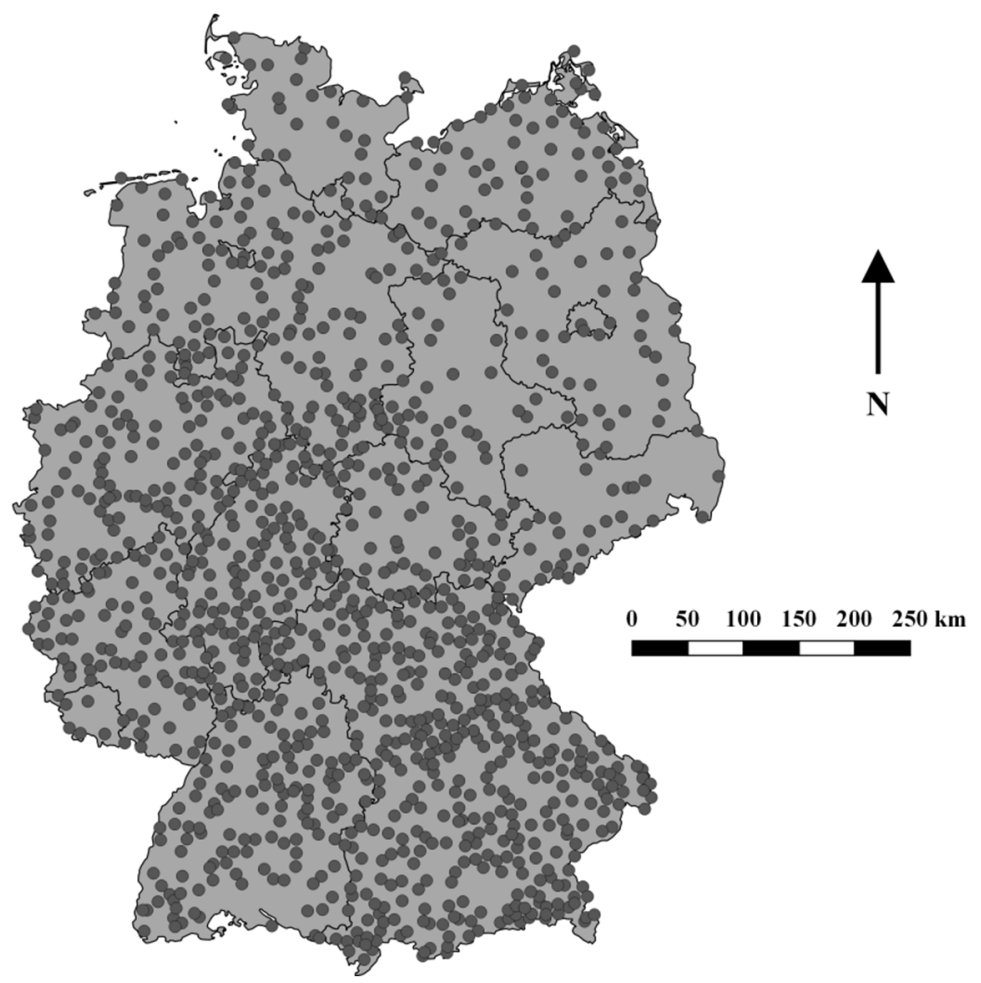

Fig. 1. Overview over the locations of the 1218 measuring stations; underlying shapefile: (C) GeoBasis-DE / BKG 2017 (data edited) 
The precipitation datasets for Germany have been provided by the Potsdam Institute for Climate Impact Research (Potsdam-Institut für Klimafolgenforschung, PIK). The PIK on its part has used data of the DWD for the generation of the datasets, and edited them by closing all data gaps, homogenizing the data and checking their plausibility. The data contain time series of daily precipitation values $[\mathrm{mm} / \mathrm{d}]$ for the period $1950-2010$ based on real observations for 1218 measuring stations, whose locations are displayed in Figure 1. A time series of 61 years of daily observations is a reliable basis for trend detection due to climate change.

\section{Drought Definition}

One aspect of importance for drought analysis is the underlying definition. The Intergovernmental Panel on Climate Change, which assesses and publishes the latest research on climate change, states that the observed global drought trends can be confirmed only with a low level of confidence, and two of the main reasons are "dependencies of inferred trends on the choice of the definition for drought" as well as "geographical inconsistencies in drought trends" (IPCC 2014).

Possible approaches of classifying drought definitions are conceptual, operational and disciplinary approaches, of which we here focus on the disciplinary point of view. According to this concept, drought definitions have been grouped as follows: meteorological, hydrological, agricultural, and socioeconomic. As a basis of meteorological drought definitions, in many cases the degree of dryness as well as the length of dry spells are used (Wilhite, Glantz 1985, Subrahmanyam 1967). In this study, we are using different indices for analysing meteorological drought.

As "precipitation-free" or "dry" we are assuming precipitation values of $1 \mathrm{~mm}$ or less, which is in accordance with the literature. Basis for this decision is that even rainwater amounts of $1 \mathrm{~mm} / \mathrm{d}$ are still so small that the water only moistens the soil's top layer and then evaporates, but it does not infiltrate into deeper soil layers, and thus neither contributes to the groundwater recharge nor becomes available to the plants (Wójcik et al. 2017).

\section{Drought Indices}

There are many existing indices and parameters for analysing drought, of which some of the best known are the Standardized Precipitation Index (SPI), the Standardized Precipitation Evapotranspiration Index (SPEI) and the (self calibrated) Palmer Drought Severity Index ((sc-) PDSI) (Bender, Schaller 2014).

In contrast to these indices, the focus of this study lies on investigating the number and distribution of dry days on different time scales. We are using the highest annual number of consecutive dry days, CDD, which is an existing index, and the lowest precipitation within $x$ consecutive days during one year as a new index, as an approach similar to low flow analysis. For the number of days, $x=40$ is an appropriate number for Germany $\left(I_{P_{\min }, 40}\right.$; see Skierlo et al. 2017). In 
addition, we analyse the annual and monthly total number of precipitation-free days as well as the total precipitation and its daily average on a monthly basis as further meteorological parameters.

\section{Trend Calculation and Trend Test}

On the basis of the presented indices, trend lines are calculated in the next step by fitting a linear regression function to the data pairs of the calculated index values and the years. This linear trend line's slope value is an indicator of the direction (the sign, positive or negative) and the magnitude of the trend. In the literature, climate trends based on temperature and precipitation data ranging over various decades are generally represented by linear trend lines, which allows an easier comparison between trends and reduces the calculation effort (IPCC 2014, Schönwiese, Janoschitz 2008).

After calculating the trend lines, in the next step the significance of the trends is checked by applying the Mann-Kendall trend test. This test is based on rank correlation and tests for monotonous up- or downward trends without requiring normal distribution of the data or linearity of the trend (Mann 1945, Kendall 1975). The chosen significance level is 0.05 .

\section{RESULTS AND DISCUSSION}

Trend lines are computed for each drought index at each station (Fig. 1, right shows an example). All 1218 measuring stations are analyzed and box plots built (Fig. 1, left). The median trend is used to make a statement of whether there is an overall trend or not. In the example of Figure 1 it can be observed that the median is positive and that close to $75 \%$ of the stations display positive trends.
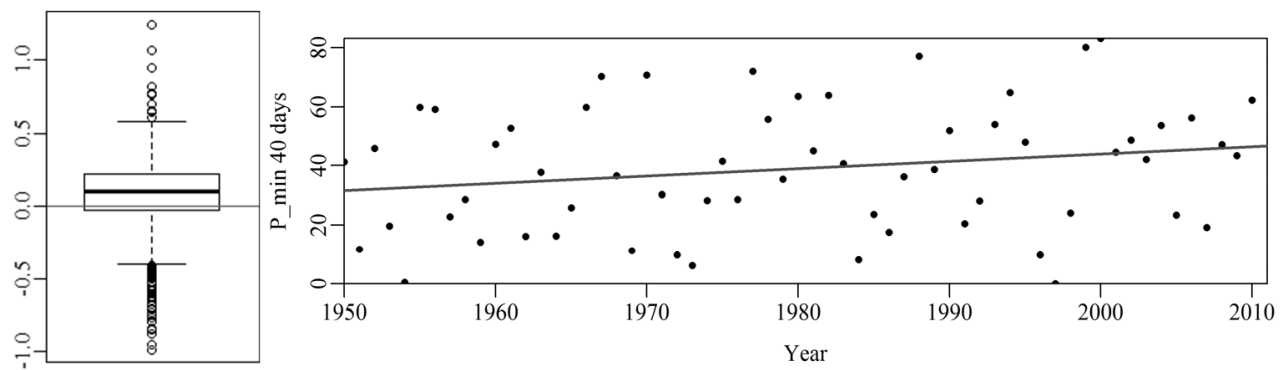

Fig. 2. Boxplot of the slope values of the trend lines for the total precipitation in January (left) and example of the linear trend line fitted to the annual index values (right)

Following this approach, the monthly precipitation shows an increasing trend for the majority of months, which means that the total precipitation during these months tends to increase. Only April and June show decreasing trends, August a slightly decreasing trend and July no tendency at all. 
Regarding the monthly number of precipitation-free days, there are mostly negative trends in the winter months (fewer dry days) and mostly positive trends in the summer months (increasing number of dry days). To be more precise, the months from October to March show negative trends (except January, which shows no tendency), and April to September showing positive trends (except May with only a slightly positive trend and July with a slightly negative trend). The annual number of dry days shows an overall negative trend, as does the consecutive number of dry days per year. Accordingly, the lowest total precipitation in 40 days mainly has increased, with a considerable north-south gradient of the values.

After the application of the Mann-Kendall trend test, it results that only a low percentage of the measuring stations show trends that can be classified as significant. In other words, the linear trends of the majority of the measuring stations are insignificant. Regarding the indices calculated on an annual basis, the index $I_{P_{m i n}, 40}$ (lowest precipitation in 40 days) shows significant trends for more than one fifth of all stations, whereas in case of the index CDD, not even 5\% of all stations show significant trends.

With respect to the monthly number of dry days and the monthly total precipitation, March is the only month for which a high percentage of all measuring stations show significant trends. In total, the trends of approximately half of all 1218 stations are significant for March.

Our results are in accordance with the literature, with respect to the general trends as well as to the lack of significance for the majority of the stations. The negative trend of precipitation-free days in winter and the positive trend in summer indicate the seasonal redistribution of precipitation (Schönwiese, Janoschitz 2008).

\section{CONCLUSIONS}

The data basis of corrected and gapless observations of daily precipitation values during 61 hydrological years with a satisfying spatial resolution allowed us to analyse trends in the precipitation regime and meteorological drought in Germany due to climate change. To sum up, the trends calculated from the drought indices and meteorological parameters show a regional variability as well as seasonality, but only a low percentage of the stations actually show significant trends as to the Mann-Kendall trend test. The month with the most significant trends is March.

\section{Acknowledgements}

We would like to thank the Deutscher Wetterdienst (DWD) and the Potsdam-Institut für Klimafolgenforschung (PIK) for kindly providing the data basis that was necessary to work on this research project. DWD climate stations: data of the climate stations of the Deutscher Wetterdienst, Offenbach, 2010. 


\section{REFERENCES}

1. Bender, S., Schaller, M. (2014), Vergleichendes Lexikon - Wichtige Definitionen, Schwellenwerte und Indices aus den Bereichen Klima, Klimafolgenforschung und Naturgefahren, Climate Service Center, $126 \mathrm{pp}$.

2. IPCC (2014), Climate Change 2014 - Synthesis Report. Contribution of Working Groups I, II and III to the Fifth Assessment Report of the Intergovernmental Panel on Climate Change, Core Writing Team; Pachauri, R. K.; Meyer, L. A. (eds.), IPCC, Geneva, Switzerland, 151 pp. ISBN: 978-92-9169-143-2

3. Kendall, M. G. (1975), Rank Correlation Methods. Charles Griffin \& Company. 4ths edition (first edition 1948), London

4. Mann, H. B. (1945), Nonparametric Tests Against Trend. Econometrica, 13, 3, 245-259

5. Schönwiese, C.-D., Janoschitz, R. (2008), Klima-Trendatlas Deutschland 19012000, Institut für Atmosphäre und Umwelt, Eigenverlag des Instituts, Frankfurt/Main. Berichte des Instituts für Atmosphäre und Umwelt der Universität Frankfurt/Main, 4

6. Skierlo, F., Miegel, K., Gómez-Hernández, J. J. (2017), New Precipitation Indices for Monitoring Drought - An Analysis of the Precipitation Regimes of Germany and the Iberian Peninsula in the Course of Climate Change. In: SGEM 2017 Vienna GREEN Conference Proceedings, 17, 43, 453-460. ISBN: 978-619-740828-7. doi: 10.5593/sgem2017H/43/S19.057. 17th International Multidisciplinary Scientific GeoConference SGEM 2017, Vienna, 27-29.11.2017

7. Statistisches Bundesamt (2015), Statistisches Jahrbuch 2015 - Deutschland und Internationales, Wiesbaden. ISBN: 978-3-8246-1037-2

8. Subrahmanyam, V. P. (1967), Incidence and Spread of Continental Drought. Reports on WMO/IHD Projects, 2, World Meteorological Organization, International Hydrological Decade, Geneva, Switzerland

9. Wilhite, D. A., Glantz, M. H. (1985), Understanding: the Drought Phenomenon The Role of Definitions. Water International, 10, 3, 111-120. doi: 10.1080/ 02508068508686328

10. Wójcik, K., Treder, W., Zbudniewek, A. (2017), Estimation of Plant Water Requirements during Sequences of Days without Precipitation in 2011-2015. Infrastructure and Ecology of Rural Areas, II/1/2017, English Edition, 611-624. doi: 10.14597/ infraeco.2017.2.1.047 